\title{
Electrochemiluminescence of Luminol Investigated by Electrochemical Impedance Spectroscopy
}

\author{
Masayuki ITAGAKI, * Emi KASUGAI, Nao KoBARI and Kunihiro WATANABE
}

\begin{abstract}
Department of Industrial Chemistry, Faculty of Science and Technology, Science University of Tokyo (Noda, Chiba, 278-8510, Japan)
\end{abstract}

Received June 26, 2000 ; Accepted October 3, 2000

\begin{abstract}
The electrochemiluminescence (ECL) of luninol in a hydrogen peroxide solution was studied by an electrochemical impedance spectroscopy (EIS). Parallel Pt wire electrodes in a flow-type spiral cell were used for the measurements of ECL. A superoxide ion, $\mathrm{O}_{2}{ }^{-}$, was generated by electrooxidation of $\mathrm{H}_{2} \mathrm{O}_{2}$ on $\mathrm{Pt}$, and a luminol was oxidized on $\mathrm{Pt}$. The oxidized luminol fluoresces by a reaction with $\mathrm{O}_{2}{ }^{-}$. An ECL impedance $L$, which is the ratio of the luminescence amplitude to the current in the frequency domain, was measured. By comparing the theoretical equation with the experimental results of $L$, the rate constant for luminol luminescence was determined.
\end{abstract}

Key Words : Electrochemiluminescence, Electrochemical Impedance Spectroscopy (EIS), ECL Impedance, Luminol

\section{Introduction}

Fluorescence emission from molecules excited by a chemical reaction is called electrochemiluminescence (ECL). ") The ECL is expected as trace analyses of metallic ions and radical ions because the background signal in detection is quite small. Collinson et. al. ${ }^{2)}$ performed ECL using a high-frequency potential pulse with a microelectrode, and determined the ion-annihilation rate constant of 9,10-diphenylanthracene. Okajima et. al.$^{3,4)}$ studied ECL by the reaction of $\mathrm{O}_{2}{ }^{-}$and 6-(4-Methoxyphenyl)-2-methylimidazo $[1,2-\mathrm{a}]$ pyrazin-9 $(7 \mathrm{H})$-one (MCLA). They ${ }^{3,4)}$ stated that the ECL of MCLA was controlled by a redox reaction of $\mathrm{O}_{2} / \mathrm{O}_{2}{ }^{-}$. Oyama et. al. ${ }^{5}$ ) applied the stopped-flow method to the ECL by reactions of oxidized and reduced species generated on anodic and cathodic electrodes respectively. Arai et. $a l .{ }^{6}{ }^{6}$ developed the trace analysis of $N$-(4-aminobutyl)- $N$-ethylisoluminol (ABEI) by ECL with flow-injection analysis (FIA). They ${ }^{6}$ ) determined ABEI of $6.0 \times 10^{-15} \mathrm{~mol} / \mathrm{dm}^{3}$ as the detection limit in a hydrogen peroxide solution.

The luminol is a highly sensitive reagent as CL analysis, because its luminescence quantum efficiency is extremely large. In the previous report, ${ }^{7)}$ a frequencydomain analysis was applied to the study of ECL of ABEI. The electrochemical impedance, which can characterize the ECL reaction mechanism in the frequency domain, was measured by imposing a sinusoidal potential perturbation. Moreover, an ECL impedance, which is a new transfer function corresponding to the ratio of luminescence amplitude to the current in the frequency domain, was determined. In the present study, the frequencydomain analysis is used for the detailed investigation of luminol luminescence, and the kinetics of ECL is discussed.

\section{Experimental}

The details of the electrochemical cell and the instru- ments were described in the previous report. ${ }^{7)}$ Electrochemical measurements were performed by a twoelectrode system. Both the working and counter electrodes were $\mathrm{Pt}$ wires whose diameter was $0.5 \mathrm{~mm}$. The two parallel Pt wires were set in the spiral channel. The distance between two electrodes was $0.6 \mathrm{~mm}$. The length of each electrode in contact with the electrolyte was 16 $\mathrm{cm}$. The working electrode joined the solution inlet at the center of the spiral channel. The counter electrode was inserted into the channel from the solution outlet. This cell was located in front of a photomultiamplifer in the $\mathrm{CL}$ detector. The electrolyte was an aqueous solution containing $\mathrm{H}_{2} \mathrm{O}_{2}$ and luminol. The $\mathrm{pH}$ of the electrolyte was adjusted by $4 \times 10^{-3} \mathrm{~mol} / \mathrm{dm}^{3} \mathrm{Na}_{2} \mathrm{HPO}_{4}$ and a 1.0 $\mathrm{mol} / \mathrm{dm}^{3} \mathrm{NaOH}$ solution. The electrolyte was prepared by doubly distilled water and analytical grade reagents. The electrolyte solution was flowed into the CL detector (Soma, S3400) by a microtube pump (Tokyo Rikakiki, MP3N). The CL detector was designed for highfrequency measurements. Since the time constant of the $\mathrm{CL}$ detection was $1 \mathrm{kHz}$, a reliable frequency response of $\mathrm{ECL}$ could be obtained below $100 \mathrm{~Hz}$. The flow rate of the electrolyte solution was $2 \mathrm{~cm}^{3} / \mathrm{min}$. The current and potential were controlled by a potentio-galvanostat (Hokuto, HA501G). In measuring the current-potential (I-E) curve, the current and the amplitude of the luminescence were recorded by two recorders (Nihon Denshikagaku, U228). In a frequency-domain measurement, the current, potential and luminescence amplitude were sent into a frequency-response analyzer (FRA) (NF, 5020).

In the measurement of $I-E$ curve, the potential of the working electrode against the counter electrode was scanned at $0.1 \mathrm{~V} / \mathrm{min}$ using a function generator (Hokuto, HB111). In a frequency-domain measurement, a $10 \mathrm{mV}$ sinusoidal potential signal between $10 \mathrm{mHz}$ and $10 \mathrm{kHz}$ was superimposed on the working electrode potential. The potential and the current responses were sent into 
FRA for an electrochemical impedance measurement. The current and the luminescence responses were sent into FRA for an ECL impedance measurement. The control of FRA and the data processing were performed by the desk-top computer (NEC, PC98).

\section{Results and Discussion}

\section{3. $1 \quad I-E$ and $P-E$ curves and luminescence reaction}

Figure 1 shows $I-E$ and $P-E$ curves in a pH 12.5 solution containing $1 \times 10^{-9} \mathrm{~mol} / \mathrm{dm}^{3}$ luminol and various concentrations of $\mathrm{H}_{2} \mathrm{O}_{2}$. In the present paper, the dimension of the ECL amplitude is represented by V, which is the output signal of the $\mathrm{CL}$ detector. A oxidation current of $\mathrm{H}_{2} \mathrm{O}_{2}$ flowed from $0.0 \mathrm{~V}$, and increased abruptly due to $\mathrm{O}_{2}$ evolution by $\mathrm{H}_{2} \mathrm{O}$ oxidation above $0.7 \mathrm{~V}$. The luminescence was observed approximately above $0.2 \mathrm{~V}$, and decreased at $\mathrm{H}_{2} \mathrm{O}$ oxidation potential. Both the current and the luminescence amplitude increased with increasing $\mathrm{H}_{2} \mathrm{O}_{2}$ concentration. It was difficult to judge which luminescence originated from the working electrode or the counter electrode, because both the working and counter electrodes were located in front of the photomultiamplifer. Arai $e t . a l{ }^{6}{ }^{6)}$ reported by a three-electrode system that the luminescence was caused by an anodic reaction in a solution containing $\mathrm{ABEI}$ and $\mathrm{H}_{2} \mathrm{O}_{2}$. Therefore, it is concluded that the luminol luminescence occurred by radical formation by $\mathrm{H}_{2} \mathrm{O}_{2}$ oxidation on the anodic working electrode at positive potentials. Comparing Figs. 1 (a) and (b), it was found that the oxidation potential (above $0.0 \mathrm{~V})$ of $\mathrm{H}_{2} \mathrm{O}_{2}$ is different from the fluorescence potential (above $0.2 \mathrm{~V}$ ). This discrepancy means that the fluores-
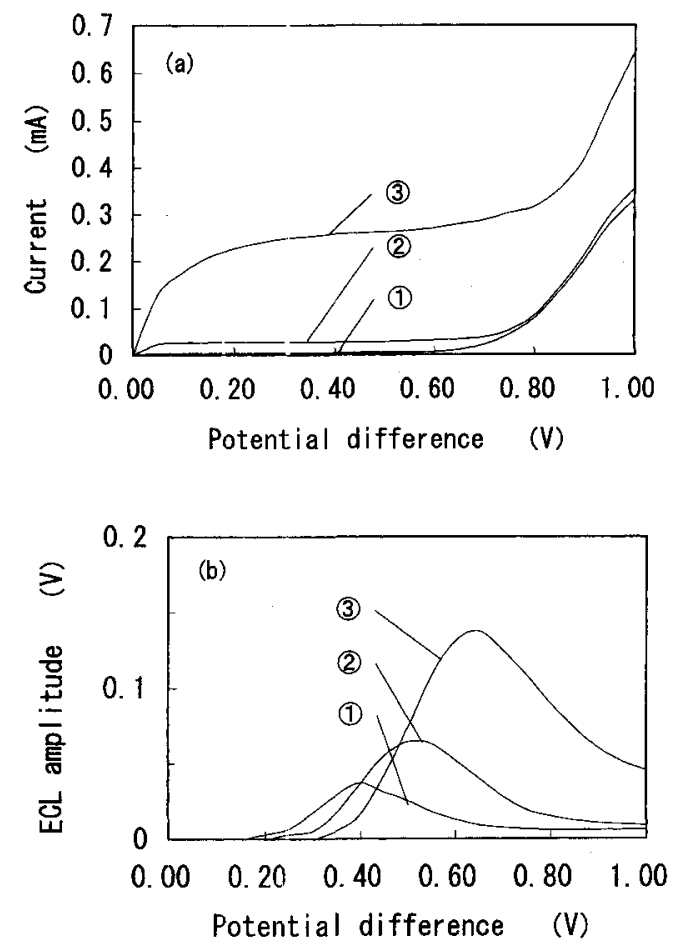

Fig. $1 I-E$ and $P-E$ curves in a solution of $\mathrm{pH} 12.5$ containing $1.0 \times 10^{-9} \mathrm{~mol} / \mathrm{dm}^{3}$ luminol. The concentrations of $\mathrm{H}_{2} \mathrm{O}_{2}$ are (1) $1.0 \times 10^{-5} \mathrm{~mol} / \mathrm{dm}^{3}$, (2) $1.0 \times 10^{-4} \mathrm{~mol} / \mathrm{dm}^{3}$ and (3) 1.0 $\times 10^{-3} \mathrm{~mol} / \mathrm{dm}^{3}$. The scan rate of the potential was $0.1 \mathrm{~V} /$ $\min$. cence does not originate from only the reaction of luminol and oxidized $\mathrm{H}_{2} \mathrm{O}_{2}$. In order to investigate another reaction, $I-E$ curves were measured in the solution containing no $\mathrm{H}_{2} \mathrm{O}_{2}$ and high concentration of luminol, and are shown in Fig. 2. Another oxidation wave is observed above $0.2 \mathrm{~V}$, and this potential agrees with fluorescence potential in Fig. 1 (b). Moreover, the current between 0.2 $\mathrm{V}$ and $1.0 \mathrm{~V}$ increases with increasing the luminol concentration. These results indicate that the oxidation of luminol is necessary for the luminescence.

Figure 3 shows the effects of $\mathrm{pH}$ on $I$ and $P$ at $0.6 \mathrm{~V}$ in the solution containing $1.0 \times 10^{-9} \mathrm{~mol} / \mathrm{dm}^{3}$ luminol and $3.0 \times 10^{-4} \mathrm{~mol} / \mathrm{dm}^{3} \mathrm{H}_{2} \mathrm{O}_{2}$. The peak of luminescence is around $0.6 \mathrm{~V}$ in the present condition. The current does not depend on the $\mathrm{pH}$, and the maximum peak of luminescence is at $\mathrm{pH} 11$. Therefore, the experiments described later are measured in the solution of $\mathrm{pH} 11$.

The influences of the reactant concentrations on $I$ and $P$ were investigated. Figure 4 shows $\log$-log plots of $I$ and $P$ against the $\mathrm{H}_{2} \mathrm{O}_{2}$ concentration at $0.60 \mathrm{~V}$ in a solution containing $1.0 \times 10^{-9} \mathrm{~mol} / \mathrm{dm}^{3}$ luminol. The values of $I$ and $P$ increase with the increase of $\mathrm{H}_{2} \mathrm{O}_{2}$ concentration, indicating that $\mathrm{H}_{2} \mathrm{O}_{2}$ was oxidized by an electrochemical reaction. Figure 5 shows plots of $P$ and the luminol concentration at $0.60 \mathrm{~V}$ in a solution containing $3.0 \times 10^{-4}$ $\mathrm{mol} / \mathrm{dm}^{3} \mathrm{H}_{2} \mathrm{O}_{2}$. The $P$ increases with increasing luminol concentration. The current presented in Fig. 5 is not influenced by the luminol concentration because the con-

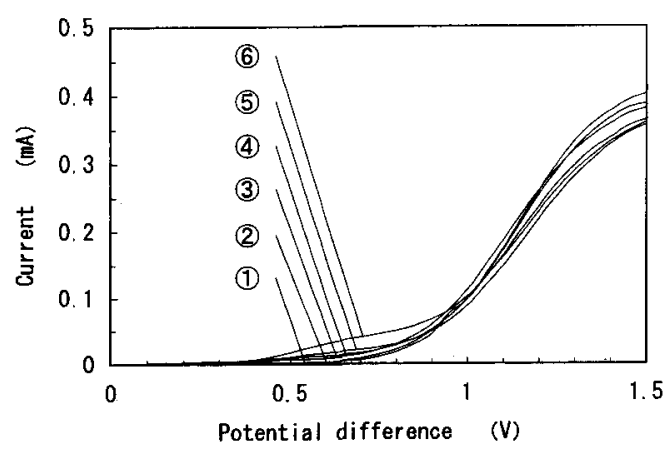

Fig. $2 I-E$ curves in a solution of $\mathrm{pH} 11$ containing no $\mathrm{H}_{2} \mathrm{O}_{2}$. The concentrations of luminol are (1) $0 \mathrm{~mol} / \mathrm{dm}^{3}$, (2) $1.0 \times$ $10^{-6} \mathrm{~mol} / \mathrm{dm}^{3}$ and (3) $1.0 \times 10^{-5} \mathrm{~mol} / \mathrm{dm}^{3}$, (4) $2.5 \times 10^{-5} \mathrm{~mol} /$ $\mathrm{dm}^{3}$, (5) $5.0 \times 10^{-5} \mathrm{~mol} / \mathrm{dm}^{3}$ and (6) $1.0 \times 10^{4} \mathrm{~mol} / \mathrm{dm}^{3}$. The scan rate of the potential was $0.1 \mathrm{~V} / \mathrm{min}$.

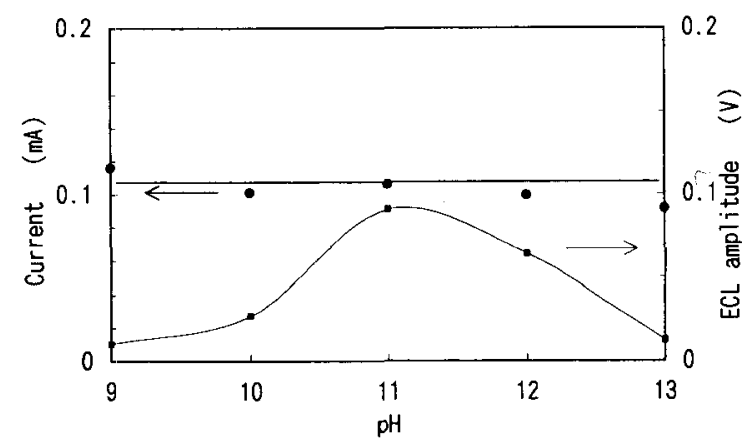

Fig. 3 Plots of current and ECL amplitude against $\mathrm{pH}$ at 0.6 $\mathrm{V}$ in a solution containing $1.0 \times 10^{-9} \mathrm{~mol} / \mathrm{dm}^{3}$ luminol and $3.0 \times 10^{4} \mathrm{~mol} / \mathrm{dm}^{3} \mathrm{H}_{2} \mathrm{O}_{2}$. 


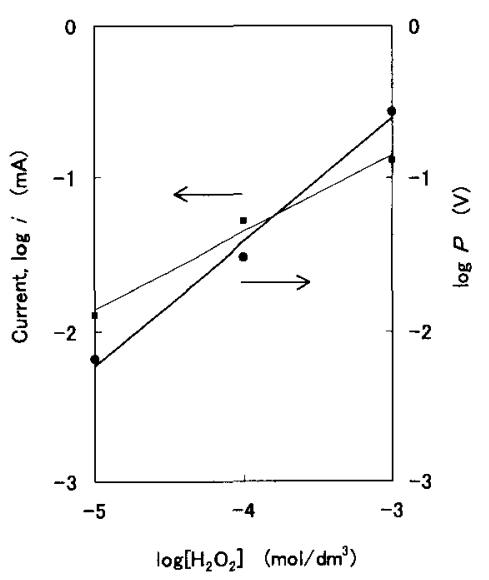

Fig. 4 Log-log plots of current and ECL amplitude against $\mathrm{H}_{2} \mathrm{O}_{2}$ concentration at $0.6 \mathrm{~V}$ in the solution of $\mathrm{pH} 11$ containing $1.0 \times 10^{-9} \mathrm{~mol} / \mathrm{dm}^{3}$ luminol. The square and circle symbols denote the current and the ECL amplitude, respectively.

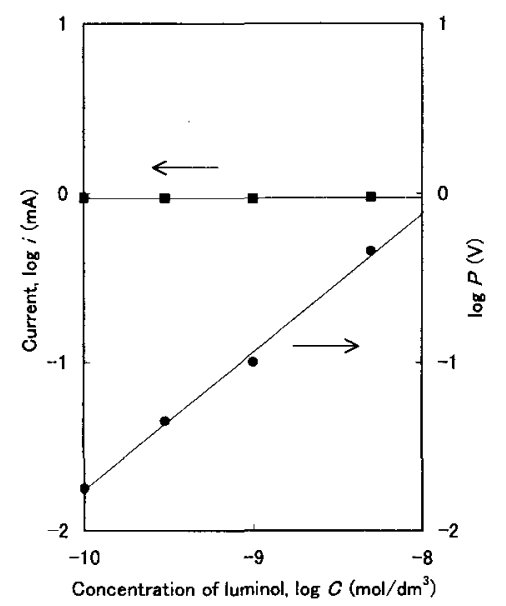

Fig. 5 Log-log plots of the current and ECL amplitude against the luminol concentration at $0.6 \mathrm{~V}$ in a solution of $\mathrm{pH}$ 11 containing $3.0 \times 10^{-4} \mathrm{~mol} / \mathrm{dm}^{3} \mathrm{H}_{2} \mathrm{O}_{2}$. The square and circle symbols denote the current and the ECL amplitude, respectively.

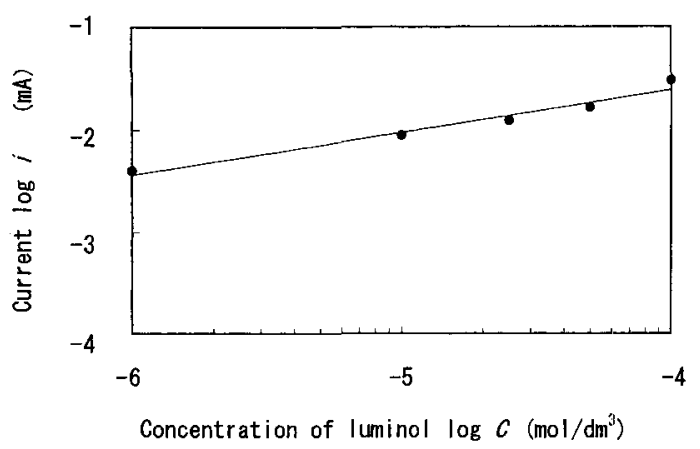

Fig. 6 Log-log plots of the current and the luminol concentration at $0.6 \mathrm{~V}$ in a solution of $\mathrm{pH} 11$ containing no $\mathrm{H}_{2} \mathrm{O}_{2}$.

centration of luminol is much smaller than that of $\mathrm{H}_{2} \mathrm{O}_{2}$. Figure 6 shows the plot of $I$ against the luminol concentration. The current increases with the luminol concentration in the case of the high concentration, indicating that the luminol was oxidized on Pt. From these results, it can be concluded that both $\mathrm{H}_{2} \mathrm{O}_{2}$ and luminol are oxidized on $\mathrm{Pt}$, and that the luminescence was due to a re- action of two products by electrochemical reactions. The ECL of luminol is divided into four processes as follows: ${ }^{8)}$

(a) Dissociation of luminol in alkaline solution.

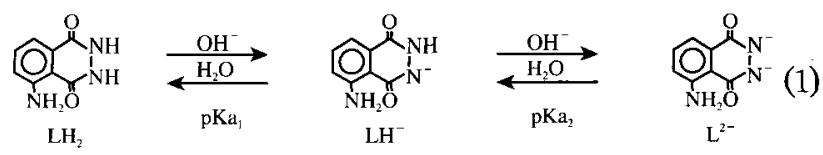

The luminol dissociates by two steps in Eq. (1). Since $\mathrm{p} K_{\mathrm{a} 1}=6.2-6.7$ and $\mathrm{p} K_{\mathrm{a} 2}=15.1$, almost species are $\mathrm{LH}^{-}$at $\mathrm{pH} 11$.

(b) Generation of super-oxide radical $\mathrm{O}_{2}{ }^{-*}$.

$$
\mathrm{H}_{2} \mathrm{O}_{2} \longrightarrow \mathrm{O}_{2}^{-*}+2 \mathrm{H}^{+}+\mathrm{e}^{-}
$$

It was reported that the radicals $\mathrm{O}_{2}{ }^{-*}$ and $\mathrm{OOH}$ were formed by the oxidation of $\mathrm{H}_{2} \mathrm{O}_{2}{ }^{91}$ Watanabe et al ${ }^{10,11)}$ stated in FIA study that the superoxide ion $\mathrm{O}_{2}{ }^{-*}$ produced from $\mathrm{H}_{2} \mathrm{O}_{2}$ reacted with 1,10-phenanthroline and emitted luminescence.

(c) Oxidation of luminol:

$$
\begin{aligned}
& \mathrm{LH}^{-} \longrightarrow \mathrm{LH}^{*}+\mathrm{e}^{-} \\
& \mathrm{LH}^{*} \underset{\mathrm{p} K_{\mathrm{a} 3}}{\rightleftarrows} \mathrm{L}^{*-}+\mathrm{H}^{+} \quad\left(\mathrm{p} K_{\mathrm{a} 3}=7.7\right)
\end{aligned}
$$

(d) Reaction of the oxidized luminol and $\mathrm{O}_{2}{ }^{-*}$.

$$
\mathrm{L}^{*-}+\mathrm{O}_{2}{ }^{-*} \longrightarrow \mathrm{AP}^{2-*}+\mathrm{N}_{2}
$$

The oxidized luminol reacts with $\mathrm{O}_{2}{ }^{-*}$ and forms an exited aminophtalate ions $\mathrm{AP}^{2-*}$. The $\mathrm{AP}^{2-*}$ decays to base state emitting fluorescence. In the case of the present ECL of luminol, the step (b) and (c) are promoted by electrochemical reactions on Pt.

On the basis of the above-mentioned results, the following reactions are considered as the present $\mathrm{ECL}$ mechanism:

$$
\begin{aligned}
& \underset{\left(\mathrm{p} K_{\mathrm{a} 1}=6.2 \sim 6.7\right)}{\mathrm{LH}_{2}} \stackrel{\mathrm{LH}^{-}}{\rightleftarrows} \underset{\left.\mathrm{p} K_{\mathrm{a} 2}=15.1\right)}{\rightleftarrows} \mathrm{L}^{2-} \\
& \mathrm{H}_{2} \mathrm{O}_{2} \longrightarrow \mathrm{O}_{2}^{-*}+2 \mathrm{H}^{+}+\mathrm{e}^{-} \\
& \mathrm{LH}^{-} \longrightarrow \mathrm{L}^{*-}+\mathrm{H}^{+}+\mathrm{e}^{-} \\
& \mathrm{L}^{*-}+\mathrm{O}_{2}{ }^{*} \longrightarrow \mathrm{AP}^{2-*}+\mathrm{N}_{2} \\
& \mathrm{AP}^{2-*} \longrightarrow \mathrm{AP}^{2-}+h v
\end{aligned}
$$

where $h v$ means a photon.

\section{2 Electrochemical and ECL impedance}

When the small perturbation signal $\Delta E$ is imposed on the electrode reaction system in the frequency domain, the signal $\Delta I$ is responded. The ratio of $\Delta E$ to $\Delta I$ is the electrochemical impedance $(Z)$ at each frequency, and electrochemical reaction can be analyzed by the $Z$,

$$
Z=\Delta E / \Delta I
$$

In ECL, the amplitude of the luminescence $(\Delta P)$ is alternated with $\Delta I$. An ECL impedance $(L)$, which is the ratio 
of $\Delta P$ to $\Delta I$, was proposed in Ref. 7 as a new transfer function to investigate an electrode reaction. The ECL impedance corresponds to luminescence efficiency in the frequency domain, ${ }^{7)}$ and allows the kinetic analysis of the ECL.

$$
L=\Delta P / \Delta I
$$

Figure 7 shows Nyquist plots of the electrochemical impedance $(Z)$ measured in a $\mathrm{pH} 11$ solution containing $3 \times 10^{-4} \mathrm{~mol} / \mathrm{dm}^{3} \mathrm{H}_{2} \mathrm{O}_{2}$ and $1.0 \times 10^{-9} \mathrm{~mol} / \mathrm{dm}^{3}$ luminol. The $Z$ 's describe the loci in the forth quadrant whose real part is plus and imaginary part is minus. Since the amplitude of the sinusoidal potential signal was sufficiently small, the reaction can be regarded as being a linear system, and is interpreted by the equivalent circuit which has two time constants. The two time constants are due to the electrochemical reaction and double layer capacitance of the working and counter electrodes. However, it is impossible to determine which reaction resistance of the working electrode or the counter electrode
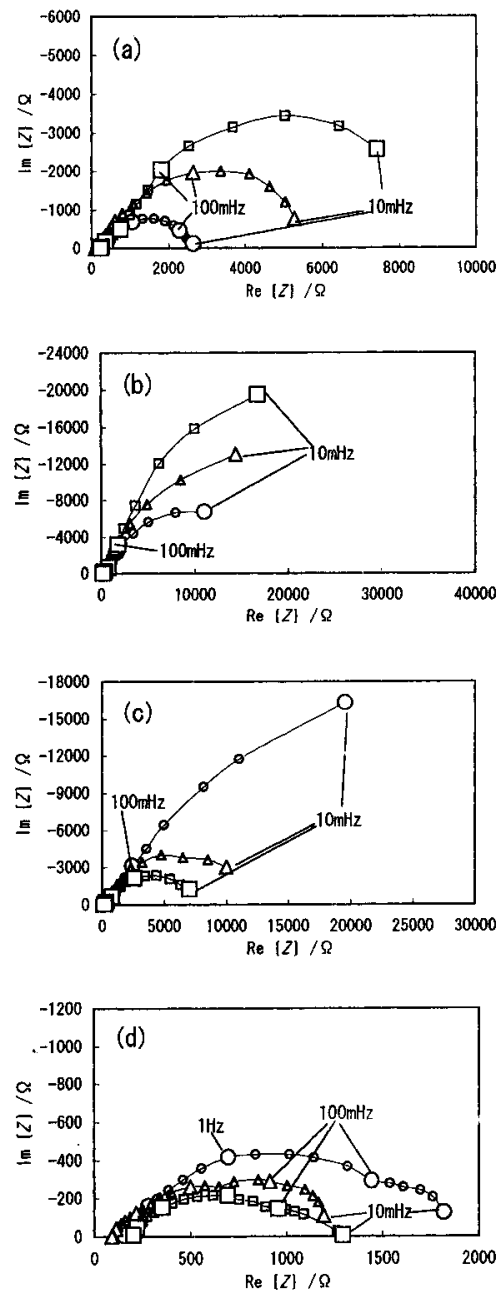

Fig. 7 Nyquist plots of electrochemical impedance $Z$ in the solution of $\mathrm{pH} 11$ containing $3.0 \times 10^{-4} \mathrm{~mol} / \mathrm{dm}^{3} \mathrm{H}_{2} \mathrm{O}_{2}$ and $1.0 \times 10^{-9} \mathrm{~mol} / \mathrm{dm}^{3}$ luminol. The potentials of the experimental results are $0.0 \mathrm{~V}(\bigcirc), 0.1 \mathrm{~V}(\triangle)$ and $0.2 \mathrm{~V}(\square)$ in (a), 0.3 $\mathrm{V}(\bigcirc), 0.4 \mathrm{~V}(\triangle)$ and $0.5 \mathrm{~V}(\square)$ in $(\mathrm{b}), 0.6 \mathrm{~V}(\bigcirc), 0.7 \mathrm{~V}$ $(\triangle)$ and $0.8 \mathrm{~V}(\square)$ in $(\mathrm{c})$, and $0.9 \mathrm{~V}(\bigcirc), 1.0 \mathrm{~V}(\triangle)$ and 1.1 $\mathrm{V}(\square)$ in (d).
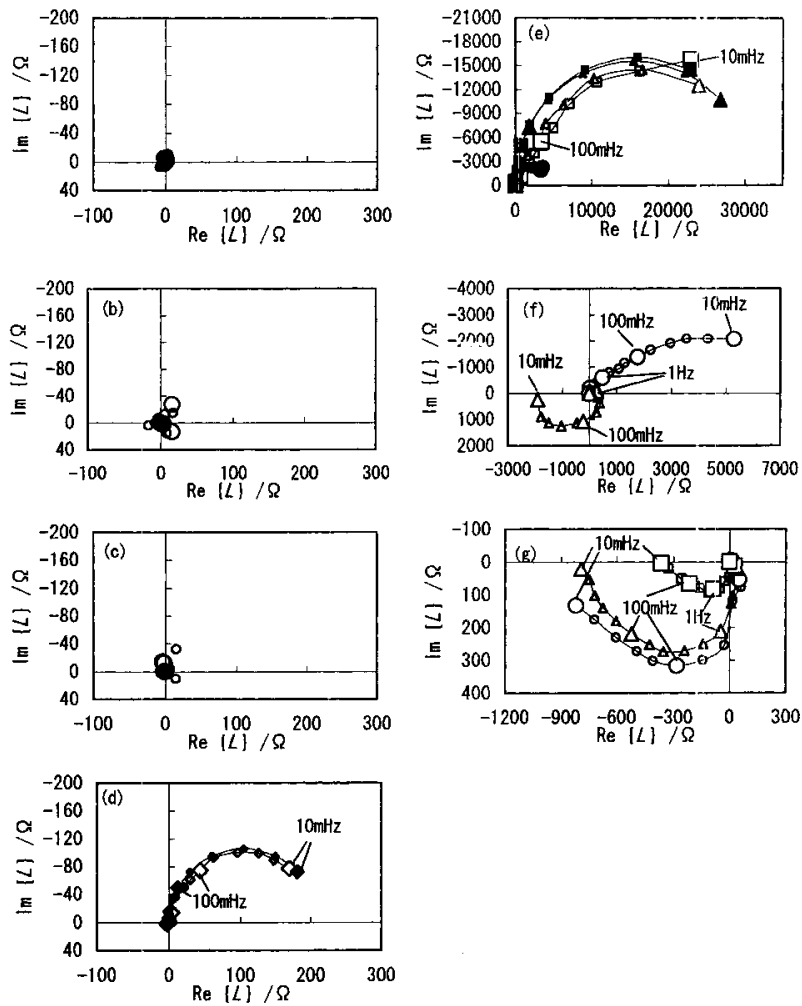

Fig. 8 Nyquist plots of ECL impedance $L$ in the same solution as Fig. 9. The open and solid symbols denote experimental and simulated results, respectively. The potentials of the results are $0.0 \mathrm{~V}(\mathrm{O})$ in $(\mathrm{a}), 0.1 \mathrm{~V}(\mathrm{O})$ in $(\mathrm{b}), 0.2 \mathrm{~V}(\mathrm{O})$ in $(\mathrm{c}), 0.3 \mathrm{~V}(\mathrm{O})$ in $(\mathrm{d}), 0.4 \mathrm{~V}(\mathrm{O}), 0.5 \mathrm{~V}(\triangle)$ and $0.6 \mathrm{~V}(\square)$ in $(\mathrm{e}), 0.7 \mathrm{~V}(\bigcirc)$ and $0.8 \mathrm{~V}(\triangle)$ in $(\mathrm{f})$, and $0.9 \mathrm{~V}(\bigcirc), 1.0 \mathrm{~V}$ $(\triangle)$ and $1.1 \mathrm{~V}(\square)$ in $(\mathrm{g})$. The parameters for the curve fitting are as follows: $a=210 \Omega, k=0.16 \mathrm{dm}^{3} \mathrm{~mol}^{-1} \mathrm{~s}^{-1}$ for 0.3 $\mathrm{V}, a=5000 \Omega, k=0.10 \mathrm{dm}^{3} \mathrm{~mol}^{-1} \mathrm{~s}^{-1}$ for $0.4 \mathrm{~V}, a=31000 \Omega$, $k=0.16 \mathrm{dm}^{3} \mathrm{~mol}^{-1} \mathrm{~s}^{-1}$ for $0.5 \mathrm{~V}, a=32000 \Omega, k=0.10 \mathrm{dm}^{3}$ $\mathrm{mol}^{-1} \mathrm{~s}^{-1}$ for $0.6 \mathrm{~V}, a=8000 \Omega, k=0.10 \mathrm{dm}^{3} \mathrm{~mol}^{-1} \mathrm{~s}^{-1}$ for $0.7 \mathrm{~V}$.

is presented in Fig. 7 in this analysis.

Figure 8 shows Nyquist plots of the ECL impedance $(L)$ measured in the same solution as shown in Fig. 7. The plots of $L$ below $0.2 \mathrm{~V}$ gather the origin of the complex plane, indicating no fluorescence emission. The $L$ describes the semicircle at the forth quadrant of the complex plane between $0.3 \mathrm{~V}$ and $0.7 \mathrm{~V}$. Above $0.8 \mathrm{~V}$, the $L$ describes the spiral shape around the origin, and approaches the minus of the real axis. Assuming that the concentrations of $\mathrm{O}_{2}^{-*}$ is $c$ in reactions (7) and (9), the mass balances of $c$ is:

$$
\mathrm{d} c / \mathrm{d} t+k c=\gamma \Delta I / F
$$

In this analysis, the oxidation current of luminol was neglected because the concentration of luminol is much smaller than that of $\mathrm{H}_{2} \mathrm{O}_{2}$. According to the previous report, ${ }^{6}$ the theoretical expression of $L$ is derived as bellow,

$$
\begin{aligned}
& L=\mathrm{a} /(1+j \omega / k) \\
& a=K \gamma / F,
\end{aligned}
$$




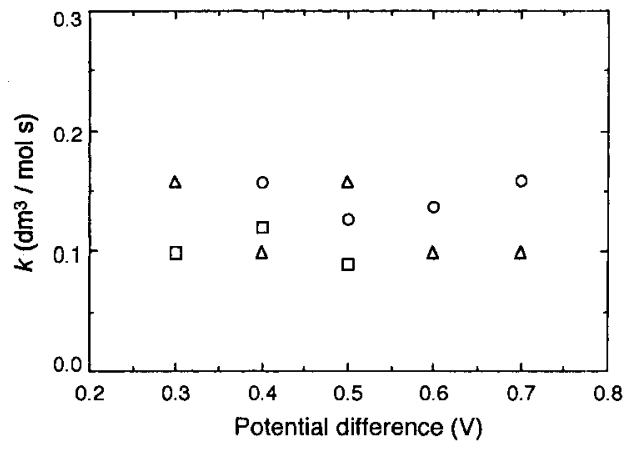

Fig. 9 Plots of reaction rate constant and potentials in the solutions of $\mathrm{pH} 11$. The concentration of chemicals are as follows: $\bigcirc: 6.0 \times 10^{-4} \mathrm{~mol} / \mathrm{dm}^{3} \mathrm{H}_{2} \mathrm{O}_{2}$ and $1.0 \times 10^{-9} \mathrm{~mol} / \mathrm{dm}^{3} \mathrm{lu}-$ minol, $\triangle: 3.0 \times 10^{-4} \mathrm{~mol} / \mathrm{dm}^{3} \mathrm{H}_{2} \mathrm{O}_{2}$ and $1.0 \times 10^{-9} \mathrm{~mol} / \mathrm{dm}^{3}$ luminol, $\square: 6.0 \times 10^{-4} \mathrm{~mol} / \mathrm{dm}^{3} \mathrm{H}_{2} \mathrm{O}_{2}$ and $1.0 \times 10^{-9} \mathrm{~mol} / \mathrm{dm}^{3}$ luminol.

where $K$ is a constant concerning the sensitivity of the detector, $j$ is an imaginary number, and $\omega$ is an angular frequency ( $\omega=2 \pi f, f$ is a frequency.). The plot of $L$ presented by equation (14) describes a semicircle on the complex plane. The experimental results of $L$ were fitted by equation (14) at $0.3-0.7 \mathrm{~V}$ in Fig. 8 . The parameter $x$ for the curve fitting are written in the caption of Fig. 8 . The obtained rate constants $(k)$ are shown in Fig. 9. In various $\mathrm{H}_{2} \mathrm{O}_{2}$ concentrations, the $k$ takes a value between 0.09 and $0.17 \mathrm{dm}^{3} \mathrm{~mol}^{-1} \mathrm{~s}^{-1}$, and the $k$ does not depend on the electrode potential since the reaction (9) is the chemical step. In Figs. 8 (f) and (g) the $L$ shows spiral shape and approaches a negative value (negative real axis) in the low-frequency range above $0.8 \mathrm{~V}$, indicating that the luminescence decreases with increasing the current. This result is in an agreement with the $P-E$ curve in Fig. 1. The negative value of $L$ can be explained by the efficiency decrease of reactions (6)-(9) to the total reaction. This luminescence requires the formation of $\mathrm{O}_{2}{ }^{-*}$ in the reaction (7). However, the formation efficiency of $\mathrm{O}_{2}{ }^{-*}$ may decrease above $0.8 \mathrm{~V}$ because $\mathrm{O}_{2}{ }^{-*}$ is an in- termediate of $\mathrm{H}_{2} \mathrm{O}_{2}$ oxidation and the final product is $\mathrm{O}_{2}$.

\section{Summary}

The ECL of luminol was investigated by electrochemical impedance spectroscopy. By the comparison of ECL impedance with the theoretical expression, the rate constant of chemical step in ECL was obtained.

The $\mathrm{CL}$ analysis is a useful method to determine trace amount of chemicals because of the small background signal. Furthermore the ECL can be used in various analyses since the catalytic reaction can be precisely controlled. The frequency-domain analysis developed in the present paper allows information concerning not only the ECL mechanism, but also the kinetic parameters.

\section{References}

1) L. R. Faulkner and A. J. Bard, Electroanalytical Chemistry, Ed. by A. J. Bard and Marcel Dekker, New York, Vol. 10, p.1 - 95 (1977).

2) M. M. Collinson and R. M. Wightman, Anal. Chem., 65, 2576 (1993).

3) T. Okajima, K. Tokuda, and T. Ohsaka, Denki Kagaku (presently Electrochemistry), 64, 12 (1996).

4) T. Okajima, K. Tokuda, and T. Ohsaka, Bioelectrochem. and Bioenerg., 41, 205 (1996).

5) M. Oyama and S. Okazaki, J. Electrochem. Soc., 144, L 326 (1997).

6) K. Arai, K. Takahashi, K. Takamura, and F. Kusu, Proceedings of 65th Meeting of Electrochemical Society of Japan, 3B11 (1998).

7) M. Itagaki, T. Kikuchi, and K. Watanabe, Anal. Sci., 15, 755 (1999).

8) I. Kamiya, Kagakuhakko, Kodansha, p.54 (1972).

9) D. T. Sawyer, A. Sobkowiak, and J. L. Roberts Jr., Electrochemistry for Chemist, John Wiley and Sons Inc., p.360 (1995).

10) K. Watanabe, T. Yamazaki, and M. Itagaki, Bunseki Kagaku, 45, 407 (1996).

11) K. Watanabe, T. Yamazaki, and M. Itagaki, Bunseki Kagaku, 45, 897 (1996). 